\title{
Single-Phase Voltage-Fed Z-Source Matrix Converter
}

\author{
Xupeng Fang* and Jie Liu*
}

\begin{abstract}
This paper proposes a novel single-phase ac-ac converter topology based on the Z-source concept. The converter provides buck-boost function and plays the role of frequency changer. Compared to the traditional ac-dc-ac converter, it uses fewer devices, realizes direct ac-ac power conversion, and has a simpler circuit structure, so as to have higher efficiency and better circuit characteristics. Compared to the traditional matrix converter, it provides a wider voltage regulation range. The circuit topology, operating principle, control method and simulation results are given in this paper, and the rationality and feasibility is verified.
\end{abstract}

\section{Keywords: Z-source matrix converter, Single-phase, AC-AC direct conversion, Simple} boost control

\section{Introduction}

To design a single-phase ac frequency changer, there are many solutions. One solution is a phase-controlled ac-ac frequency changer which uses a thyristor as the main switching device. However, it will introduce low-frequency harmonics to the power supply, and its frequency range is limited, that is, it can only output a voltage whose frequency is less than the input's, and its input-side power factor is often low. Another solution is the matrix converter, which can provide an all-silicon solution to the problem of converting ac power from one frequency to another, offering almost all the features required of an ideal static frequency changer. It possesses many advantages such as the ability to provide bidirectional power flow between the power supply and the load. Most of the contemporary modulation strategies are able to provide practically sinusoidal waveforms for the input and output currents with negligible low-order harmonics, and to control the input displacement factor. However, they have inherent disadvantages, such as low voltage gain, low reliability due to the shoot-through of the switches of the same phase leg, and control complexity.

Z-source ac-ac converter is a novel power conversion topology deduced from the basic Z-source converter concept proposed by Prof. Fang. Z. Peng in 2002 [1]. Several papers on Z-source matrix converters have been published in recent years [7-22]. Several are based on the

\footnotetext{
* College of Information \& Electrical Engineering, Shandong University of Science and Technology, China.

(xpfang69@yahoo.com.cn, xiaoyuan1987630@126.com)

Received 16 June 2011; Accepted 18 October 2011
}

Z-source inverter topology [7-9], one is based on the ac-ac cycloconverter concept [10], several are based on the concept of combining the Z-source ac-ac converter with a traditional matrix converter [11-17], and several describe the sparse matrix converter based on the Z-source concept and its control method [18-21]. This paper will analyze and describe the single-phase Z-source matrix converter which is based on the combination of Z-source ac-ac converter and traditional matrix converter topology. There are two types of Z-source matrix converter structures - voltage-fed and current-fed. (The three-phase current-fed Z-source matrix converter is described in [3].) This paper will analyze the operating principle, control strategy and voltage gain of the single-phase voltage-fed Z-source matrix converter. The simulation results will verify the rationality of the proposed converter.

\section{Single-phase Voltage-Fed Z-source Matrix Converter Topology}

Fig.1 shows the proposed Z-source matrix converter topology. It can provide bidirectional power flow. Just like other Z-source inverter or converter topologies, the Znetwork here is symmetrical, that is, the inductors L1, L2 and capacitors $\mathrm{C} 1, \mathrm{C} 2$ have the same inductance (L) and capacitance (C), respectively. Since the switching frequency of the power devices is much higher than that of the input and output voltages, the inductance and capacitance required for the Z-source network components are always low. Thus, the inductors and capacitors will not add much to the volume and weight of the whole system, 
but they will provide the unique buck-boost function, enhance the reliability of the converter, and provide ridethrough ability for the converter.

The control methods of the traditional matrix converters, e.g. sinusoidal pulse width modulation (SPWM) or space vector PWM (SVPWM), could also be applied to the voltage-fed Z-source matrix converter. Due to its unique structure, the voltage-fed Z-source matrix converter has an additional operating state: shoot-through zero state in which the output terminals of the Z-network are shorted when the switches of a phase-leg or two phase-legs are turned on simultaneously. There is no shoot-through zero state in the traditional voltage-fed single-phase matrix converter because such a state would cause a short circuit and destroy the devices. The Z-source network makes the shoot-through zero state possible, and the shoot-through zero state provides the unique buck-boost feature of the matrix converter without changing the total time interval of the active states. That is, the active states are unchanged and the output voltage is boosted because of the shoot-through zero state.

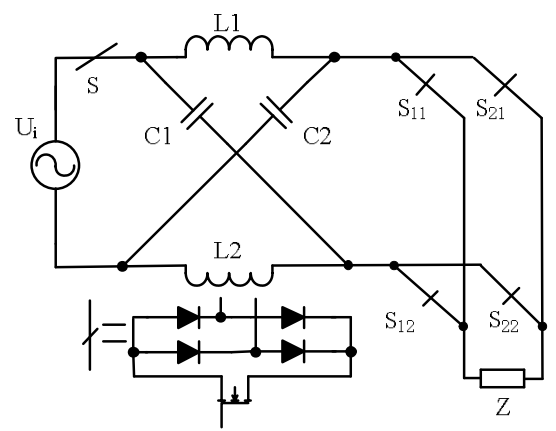

Fig. 1. Single-phase voltage-fed Z-source matrix converter topology

\section{Operating Principle and Control of the Proposed Converter}

When the converter is in the active states, switch $\mathrm{S}$ in Fig. 1 is on and the power flows to the load. The switches $\mathrm{S}_{11}, \mathrm{~S}_{12}, \mathrm{~S}_{21}$ and $\mathrm{S}_{22}$ are controlled same to the single-phase voltage-source inverter. When it is in the traditional zero states, that is, when $S_{11}$ and $S_{21}$, or $S_{12}$ and $S_{22}$ are turned on simultaneously, the load is shorted, the switch $\mathrm{S}$ is turned off, we insert an extra shoot-through zero state and make the output terminal of Z-network shorted. And then same to the operating principle of the Z-source inverter, the output of the proposed converter is boosted.

As is well-known, the traditional voltage-fed singlephase matrix converter has four switching states, or vectors: two active states and two zero states. Based on the aforementioned analysis, the proposed voltage-fed single- phase Z-source matrix converter has five switching states, that is, it has an additional switching state - the shootthrough zero state. This switching state can be realized by the following three methods: turning switches $S_{11}$ and $S_{21}$ on, or turning switches $S_{12}$ and $S_{22}$ on, or turning all four switches $S_{11}, S_{21}, S_{12}$, and $S_{22}$ on simultaneously (see Fig.1).

When the proposed converter operates in one of the active states or traditional zero states, we can obtain a general equivalent circuit as shown in Fig.2, in which the power flows to the load. It should be noted that when the converter operates in the traditional zero states, the load is separated from the power source, so its obtainable power is zero, but we can still use Fig. 2 to describe these operating states of the proposed converter. In these states, the load could be regarded as a zero-value current source.

When the proposed converter operates in the novel shoot-through zero state, we can obtain an equivalent circuit as shown in Fig.3, in which the power can not flow to the load and the matrix converter bridge is shorted.

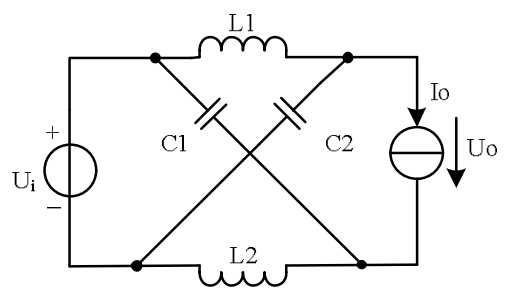

Fig. 2. Equivalent circuit when the converter operates in non-shoot-through state

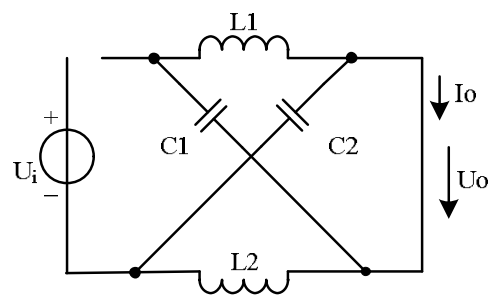

Fig. 3. Equivalent circuit when the converter operates in shoot-through zero state

According to the operating principle of a single-phase voltage-fed Z-source ac-ac converter, the average voltage of the Z-source network inductors over one ac-line period should be zero, ignoring the fundamental voltage drop. Thus, we have the relationship between the output fundamental voltage of the Z-network and the input voltage of the converter,

$$
\frac{U_{Z m}}{U_{i m}}=\frac{1-D}{1-2 D}
$$

where $\mathrm{D}$ is the duty cycle of the shoot-through zero state over the switching period, and $U_{z m}$ and $U_{i m}$ are the peak 
values of the output fundamental voltage of the Z-network and the input voltage of the converter, respectively.

The output fundamental voltage of the Z-network can be expressed as

$$
u_{Z}=U_{Z m} \sin \left(\omega_{i} t-\varphi_{Z}\right)
$$

where $\omega_{i}$ is the angular frequency and $\varphi_{Z}$ is the phase shift with respect to the converter input voltage. The phase shift is related to the switching frequency. Here, since the switching frequency is much higher than the input power frequency, $\varphi_{\mathrm{Z}}$ can be neglected [6]. If the desired output fundamental voltage of the converter is as follows:

$$
u_{o}=U_{o m} \sin \left(\omega_{o} t-\varphi_{o}\right)
$$

then, according to the conversion principle of the matrix converter, we have

$$
\left[u_{0}\right]=M\left[u_{Z}\right]
$$

where the conversion matrix $M$ of the traditional singlephase voltage-fed matrix converter can be expressed as follows:

$$
M=\left[\begin{array}{ll}
m_{11} & m_{12} \\
m_{21} & m_{22}
\end{array}\right]
$$

where $m_{11}, m_{12}, m_{21}$ and $m_{22}$ are the duty cycles of the four bi-directional switches $\mathrm{S}_{11}, \mathrm{~S}_{12}, \mathrm{~S}_{21}$ and $\mathrm{S}_{22}$ when they operate in the non-shoot-through zero states. Then, (4) is expressed as

$$
\left[\begin{array}{l}
u_{o+} \\
u_{o^{-}}
\end{array}\right]=\left[\begin{array}{ll}
m_{11} & m_{12} \\
m_{21} & m_{22}
\end{array}\right]\left[\begin{array}{c}
u_{Z} \\
0
\end{array}\right]
$$

where

$$
u_{o}=u_{o+}-u_{o-}=\left(m_{11}-m_{21}\right) u_{Z}
$$

The essential result of the matrix conversion is that, in a single switching period, the desired output voltage is the average value of a positive and a negative voltage pulse whose duty cycles are different. For the traditional matrix converter, when the load is inductive, the commutation of the switches must meet two conditions: the output phases can not be opened and the input phases can not be shorted. However, for the Z-source matrix converter, due to its unique topology structure, the input phases can be shorted and this condition does not destroy the switches. So, the single-phase Z-source matrix converter has the following operating states:

State 1: switches $S_{11}, S_{22}$ are turned on simultaneously, $u_{o}=u_{z}$. State 2: switches $S_{21}, S_{12}$ are turned on simultaneously, $u_{0}=-u_{Z}$. State 3: switches $S_{11}, S_{21}$ are turned on simultaneously, $u_{0}=0$. State 4: switches $S_{12}, S_{22}$ are turned on simultaneously, $u_{0}=0$. State 5: there are five cases: (a) switches $S_{11}, S_{21}$ and $S_{12}$ are turned on simultaneously; (b) switches $S_{11}, S_{21}$ and $S_{22}$ are turned on simultaneously; (c) switches $\mathrm{S}_{12}, \mathrm{~S}_{22}$ and $\mathrm{S}_{11}$ are turned on simultaneously; (d) switches $\mathrm{S}_{12}, \mathrm{~S}_{22}$ and $\mathrm{S}_{21}$ are turned on simultaneously; and (e) switches $\mathrm{S}_{11}, \mathrm{~S}_{12}, \mathrm{~S}_{21}$ and $\mathrm{S}_{22}$ are turned on simultaneously. These cases are all part of the shoot-through zero state, and $\mathrm{u}_{\mathrm{o}}=0$ in this state. We assume that the duty cycle of the switches that operate in this state is D. This state does not change the relationship between the input and output voltages of the matrix bridge section, but it will change the voltage gain of the Z-source section.

According to the operating process of the single-phase Zsource matrix converter and the modulation method of the traditional matrix converter, the variables $m_{11}$ and $m_{21}$ can be expressed as follows:

$$
\begin{aligned}
& m_{11}=\frac{1}{2}\left(1-D+q \frac{\sin \left(\omega_{o} t-\varphi_{o}\right)}{\sin \left(\omega_{i} t\right)}\right) \\
& m_{21}=\frac{1}{2}\left(1-D-q \frac{\sin \left(\omega_{o} t-\varphi_{o}\right)}{\sin \left(\omega_{i} t\right)}\right)
\end{aligned}
$$

where $q$ is the voltage transfer ratio of the traditional singlephase matrix converter. Evidently, $m_{11}$ and $m_{21}$ are less than 1. In the neighborhood of the input voltage near zero, if we use constant duty cycle to replace the actual duty cycle, we have

$$
\begin{aligned}
& m_{11}^{\prime}=\frac{1}{2}\left(1-D+q \frac{\omega_{o}}{\omega_{i}}\right) \\
& m_{21}^{\prime}=\frac{1}{2}\left(1-D-q \frac{\omega_{o}}{\omega_{i}}\right)
\end{aligned}
$$

Since $0 \leq m_{11}^{\prime} \leq 1$ and $0 \leq m_{21}^{\prime} \leq 1$, it is easy to obtain the following relationship:

$$
0 \leq q \frac{\omega_{o}}{\omega_{i}} \leq 1
$$

Evidently, the voltage transfer ratio of the traditional single-phase matrix converter is related to its frequency transfer ratio. That is, when the frequency is boosted, the voltage would be bucked, and vice versa.

Fig.4 shows the SPWM control principle. It describes the control signals of the five bi-directional switches, $\mathrm{S}_{11}, \mathrm{~S}_{12}$, $\mathrm{S}_{21}, \mathrm{~S}_{22}$ and $\mathrm{S}$, and all the inserted zero-state intervals $T_{0}$. Note that, in the positive half cycle of the input voltage, the control method of the matrix bridge is the same as that of the single-phase voltage-source inverter but, in the negative half cycle, we should change the control method. That is, in the negative half cycle, the lower two switches $S_{12}$ and $S_{22}$ play the role that $S_{11}$ and $S_{21}$ played in the positive half cycle, and the same applies to the upper two switches $S_{11}$ and $S_{21}$. So, the SPWM control strategy should be modified to suit this unique condition. The simple boost control method [4] is adopted, that is, two dc reference signals are compared with the carrier triangle wave to obtain the shootthrough zero-state intervals. To achieve maximum boost 
function, here we keep the value of the dc reference equal to the maximum value of the modulation sinusoidal wave. Thus, $m+D=1$ [4].

Then we have

$$
\frac{U_{o m}}{U_{Z m}}=q \times \frac{\omega_{i}}{\omega_{o}}
$$

and

$$
\frac{U_{o m}}{U_{i m}}=\frac{1-D}{1-2 D} \times \frac{\omega_{i}}{\omega_{o}}=\frac{1-D}{1-2 D} \times \frac{1}{f_{r}}
$$

where $\mathrm{f}_{\mathrm{r}}=\omega_{\mathrm{o}} / \omega_{\mathrm{i}}$ is the frequency transfer ratio of the matrix converter. From (11) we can see that the voltage gain is not only related to the duty cycle of the shoot-through zero state, but it is also related to the input and output voltage frequency ratio. When the frequency of the output voltage is higher than that of the input voltage, the overall voltage gain will be less than that of the case when the input frequency equals the output frequency. When the output frequency is lower than that of the input, the overall voltage gain will be more than that of the case when the input frequency equals the output frequency. The relationship of voltage gain versus shoot-through duty ratio $\mathrm{D}$ when the frequency ratio $f_{r}$ equals 1 is shown in Fig.5; and the relationship of voltage gain versus shoot-through duty ratio $D$ and the frequency ratio $f_{r}$ is shown in Fig.6.

From Fig.5 and Fig.6, we can see that the voltage gain of the proposed converter is more than that of the traditional single-phase matrix converter, the proposed converter has good buck/boost characteristics, and it has phase-inversion function when the duty ratio is more than 0.5 . Evidently, the duty ratio $\mathrm{D}$ is generally less than 0.5 because, as the modulation index $m$ decreases, the voltage stress of the matrix bridge switches increase.

\section{Simulation Results}

To verify the analysis above, some simulations are done using Saber software. The simulation circuit is the same as that of Fig. 1 and the simulation parameters are shown in Table 1. The switching frequency is $10 \mathrm{kHz}$. Simulation results are shown in Fig. 7 - Fig. 10.

For the simulation results in Fig.7 and Fig.8, the output frequency is $50 \mathrm{~Hz}$. By regulating the modulation index and the dc references, we can obtain buck or boost functions, and the output voltage could be in-phase or out-of-phase with the input voltage. From Fig.9 and Fig.10, we can see that the output frequency can be either higher or lower than the input frequency, we can achieve either the buck or boost function, and the phase inversion characteristic can also be achieved. The simulation results verify the aforementioned analysis.
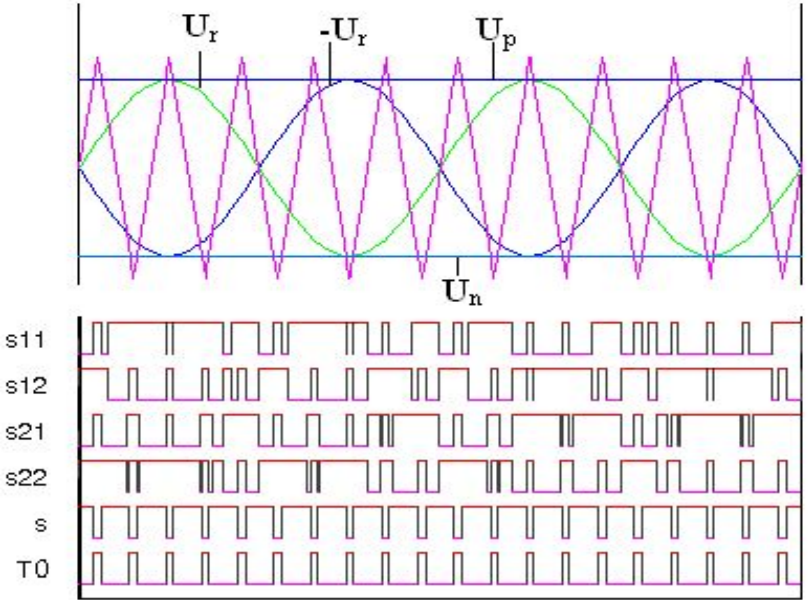

Fig. 4. Simple boost control sketch map

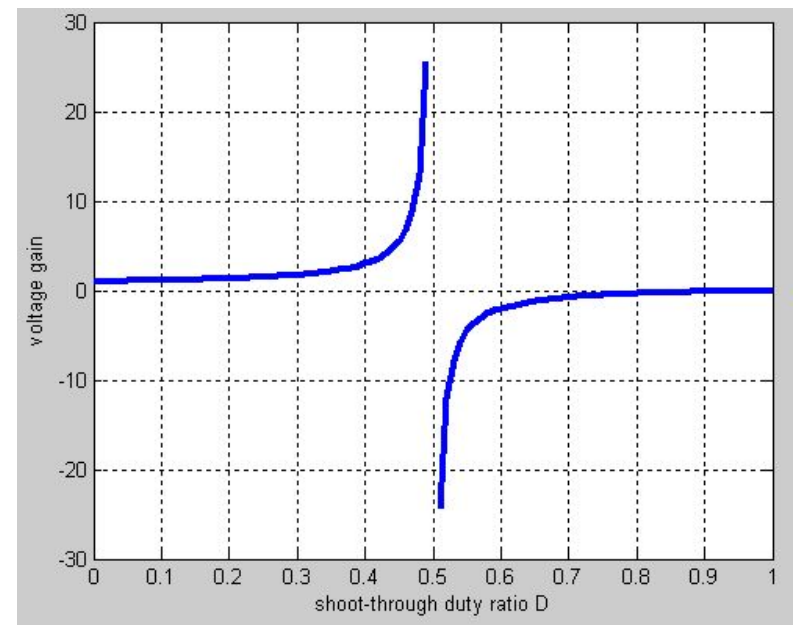

Fig. 5. Voltage gain versus shoot-through duty ratio D for $\mathrm{f}_{\mathrm{r}}=1$.

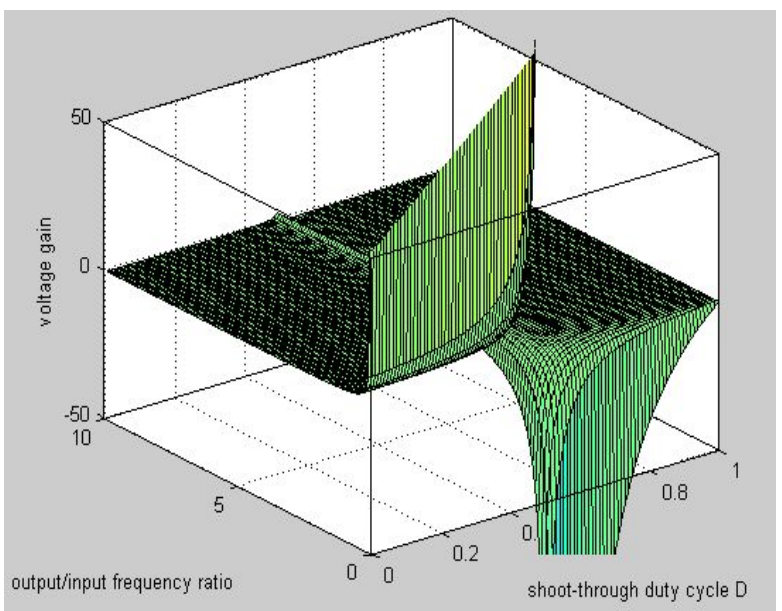

Fig. 6. Voltage gain versus shoot-through duty ratio D and frequency transfer ratio $f_{r}$ 
Table 1. Simulation parameters

\begin{tabular}{|c|c|c|c|}
\hline R-L load & $\begin{array}{c}\mathrm{R}=20 \Omega, \\
\mathrm{L}=10 \mathrm{mH}\end{array}$ & $\begin{array}{c}\mathrm{R}=20 \Omega, \\
\mathrm{L}=10 \mathrm{mH}\end{array}$ & $\begin{array}{c}\mathrm{R}=20 \Omega \\
\mathrm{L}=10 \mathrm{mH}\end{array}$ \\
\hline Voltage gain & $\mathrm{G}=2$ & $\mathrm{G}=1.25$ & $\mathrm{G}=1.2$ \\
\hline Input voltage rms & $220 \mathrm{~V}$ & $220 \mathrm{~V}$ & $220 \mathrm{~V}$ \\
\hline Output voltage rms & $440 \mathrm{~V}$ & $275 \mathrm{~V}$ & $264 \mathrm{~V}$ \\
\hline Input frequency & $50 \mathrm{~Hz}$ & $50 \mathrm{~Hz}$ & $50 \mathrm{~Hz}$ \\
\hline Output frequency & $50 \mathrm{~Hz}$ & $100 \mathrm{~Hz}$ & $20 \mathrm{~Hz}$ \\
\hline Z-network & $\begin{array}{c}\mathrm{L}=1 \mathrm{mH}, \\
\mathrm{C}=50 \mu \mathrm{F}\end{array}$ & $\begin{array}{c}\mathrm{L}=1 \mathrm{mH}, \\
\mathrm{C}=50 \mu \mathrm{F}\end{array}$ & $\begin{array}{c}\mathrm{L}=1 \mathrm{mH}, \\
\mathrm{C}=50 \mu \mathrm{F}\end{array}$ \\
\hline Output inductor & $1 \mathrm{mH}$ & $1 \mathrm{mH}$ & $4 \mathrm{mH}$ \\
\hline Output capacitor & $50 \mu \mathrm{F}$ & $150 \mu \mathrm{F}$ & $150 \mu \mathrm{F}$ \\
\hline
\end{tabular}

(A) : t(s)

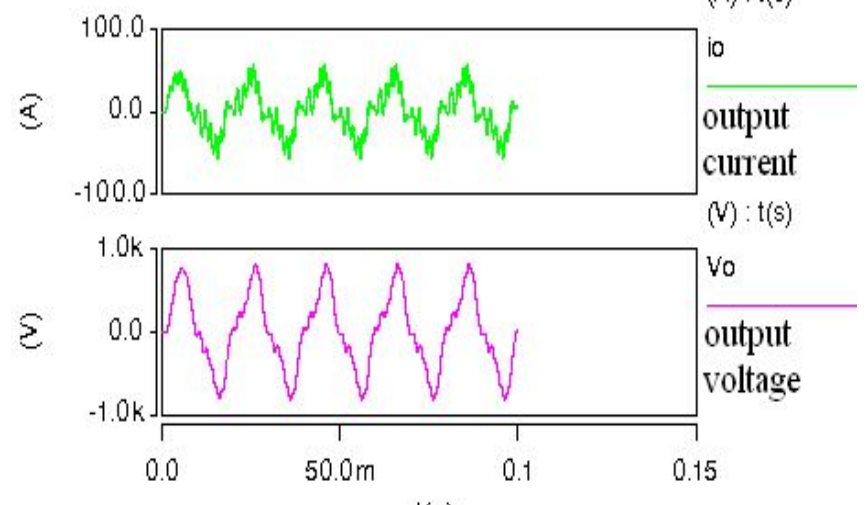

$t(s)$
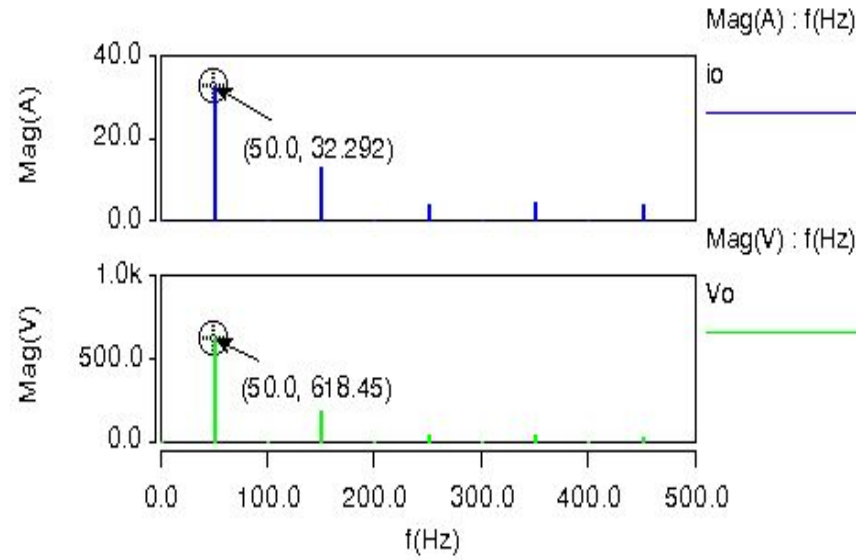

Fig. 7. Simulation results when output voltage frequency is $50 \mathrm{~Hz}$ (the output voltage is in phase with the input voltage, the voltage gain is 2 ) (v) : t(s)

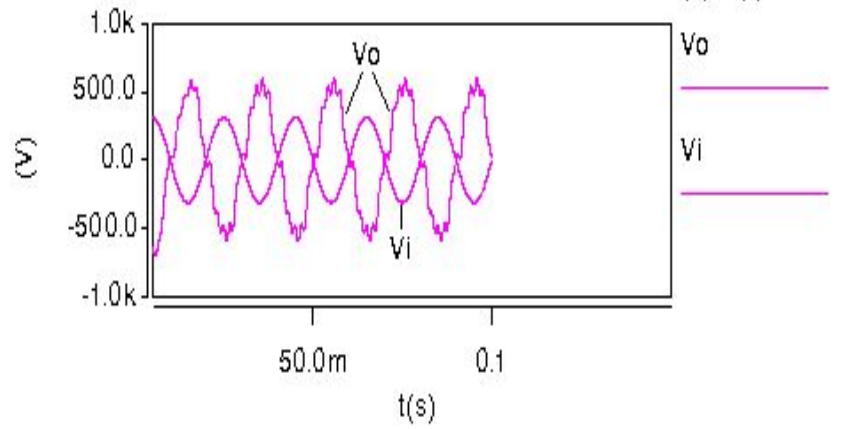

$\operatorname{Mag}(V): f(H z)$

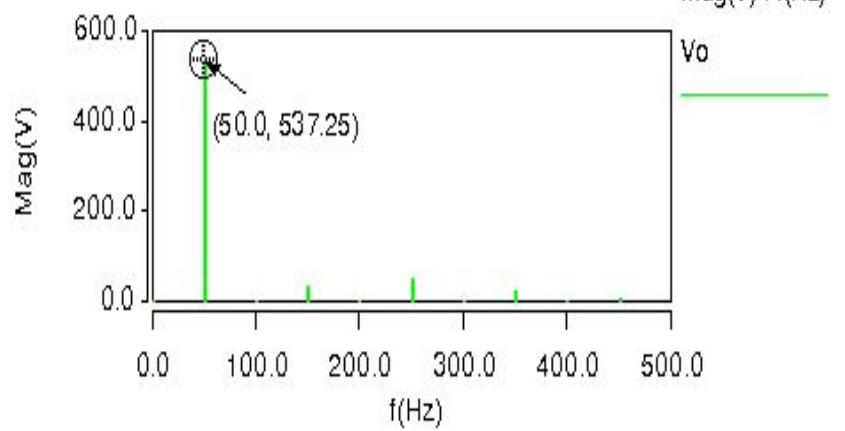

Fig. 8. Simulation results when output voltage frequency is $50 \mathrm{~Hz}$ (the output voltage is out-of-phase with the input voltage, the voltage gain is 1.73 )
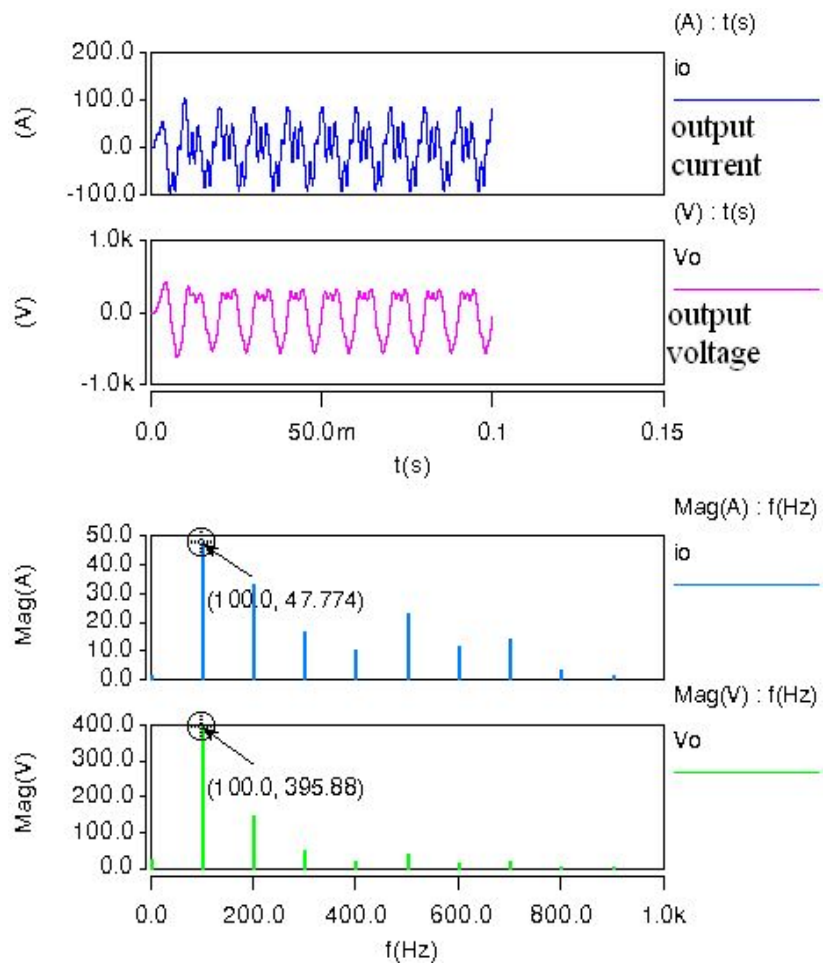

Fig. 9. Simulation results when output voltage frequency is $100 \mathrm{~Hz}$ (the output voltage is in-phase with the input voltage, the voltage gain is 1.25 ) 

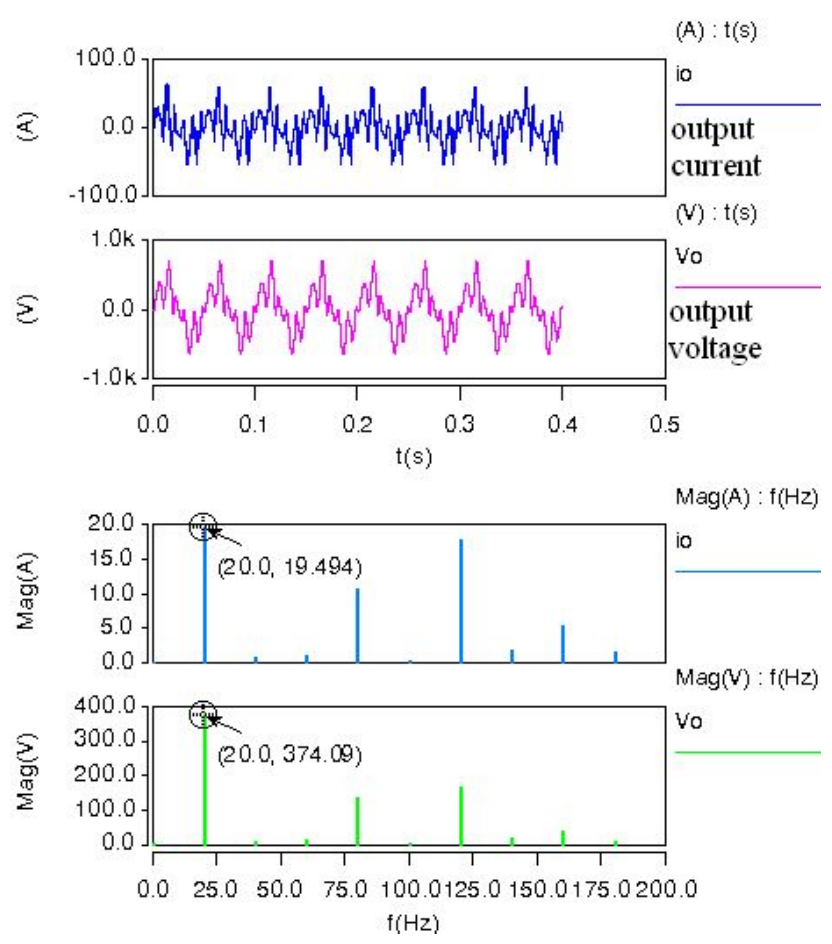

Fig. 10. Simulation results when output voltage frequency is $20 \mathrm{~Hz}$ (the output voltage is in-phase with the input voltage, the voltage gain is 1.2 )

\section{Conclusion}

This paper proposed a novel single-phase matrix converter topology, its circuit structure and operating principle were introduced, a detailed control method was given, and simulation results were also given. In this paper, the chosen control method was the simple boost control method, which is widely used in other Z-source inverter/converter topologies, such as inverter, dc-dc converter, ac-ac converter, etc. The maximum boost control method should be suitable for the proposed converter in this paper. However, due to its complicated harmonic components, it would be difficult to use with the novel Zsource matrix converter. Much more research and analysis needs to be done in future works.

\section{Acknowledgements}

The authors thank Professor Fang Z. Peng for his selfgiving guidance to this work. This work was supported by Shandong Province Natural Science Foundation (No.ZR2009FM017), China Postdoctoral Science Foundation (No.20090461254), Shandong Province Postdoctoral Innovation Project Special Foundation (No.200903034), and also supported by SDUST Research Fund (No.2010KYTD101).

\section{References}

[1] F. Z. Peng, "Z-source inverter," in Proc. IEEE Industry Applications Conference, 2002, pp.775-781.

[2] F. Z. Peng, "Z-Source Inverter," IEEE Transactions on Industry Applications, vol. 39, no.2, pp. 504-510, March/April, 2003.

[3] Xupeng Fang and Zhiqiao Chen, "Current-fed Z-source matrix converter," in Proc. IEEE International Conference on Applied Superconductivity and Electromagnetic Devices, Chengdu, China, 2009, pp. 93-96.

[4] Miaosen Shen, Jin Wang, Alan Joseph, Fang Z. Peng, Leon M. Tolbert, and Donald J. Adams, "Maximum constant boost control of the Z-source inverter," in Proc. IEEE Industry Applications Conference, 2004, pp. 142-147.

[5] W. L. Deng, X. R Yang, J. L Zhu, and L. Z. Yi, "Space vector modulation strategy of two-stage matrix converter with 18 switches and its simulation study," Proceedings of the CSEE, vol. 25, no. 15, pp. 84-90, Aug., 2005.

[6] Xupeng Fang, "Research of Z-source inverter," Ph.D. dissertation, College of Electrical Engineering, Zhejiang University, Hangzhou, China, June, 2005.

[7] Keping You and M.F. Rahman, "Constructing a novel power converter by matrix converter theory and Z-source inverter concepts for ISA $42 \mathrm{v}$ powernet system," in Proc. IEEE Industry Applications Society Annual Meeting, v 4, 2006, pp. 2101-2108.

[8] You Keping and Rahman M.F., "A new power converter for ISA $42 \mathrm{~V}$ PowerNet system using matrix converter theory and Z-source inverter concepts," in Proc. IEEE Vehicle Power and Propulsion Conference, v 2005, 2005, pp. 461467.

[9] You Keping and Rahman M.F., "A matrix-Z-source converter for automotive integrated starter alternator system," in Proc. IEEE Applied Power Electronics Conference and Exposition, 2008, pp. 273-279.

[10] M.-K. Nguyen, Y.-G. Jung, H.-Y. Yang, and Y.-C. Lim, "Single-phase Z-source cycloconverter with safecommutation strategy," IET Power Electronics, vol. 3, no. 2, pp. 232-242, Mar., 2010.

[11] Weizhang Song and Yanru Zhong, "A study of Z-source matrix converter with high voltage transfer ratio," in Proc. IEEE Vehicle Power and Propulsion Conference, 2008, pp. 467-468.

[12] Minh-Khai Nguyen, Young-Gook Jung, and Young-Cheol Lim, "Single-Phase Z-source buck-boost matrix converter," in Proc. IEEE APEC, 2009, pp. 846-850.

[13] Kiwoo Park, Sung-Tak Jou, and Kyo-Beum Lee, "Z-source matrix converter with unity voltage transfer ratio," in Proc. 35th Annual Conference of the IEEE Industrial Electronics Society, IECON 2009, 2009, pp. 4523-4528.

[14] Zhang Shao, Tseng King Jet, and Nguyen Trong Duy, "Novel three-phase AC-AC Z-Source converters using matrix converter theory," in Proc. 2009 IEEE Energy Conversion Congress and Exposition, ECCE 2009, 2009, pp. 3063-3070.

[15] Minh-Khai Nguyen, Young-Gook Jung, Young-Cheol Lim, and Young-Min Kim, "A single-phase Z-source buck-boost matrix converter," IEEE Transactions on Power Electronics, vol. 25, no. 2, pp. 453-462, Feb.17, 2010.

[16] Wei-Zhang Song, Yan-Ru Zhong, and Xiang-Dong Sun, "Zsource two-stage matrix converter with high voltage transfer ratio and immune to abnormal input voltages," Zhongguo Dianji Gongcheng Xuebao/Proceedings of the Chinese 
Society of Electrical Engineering, v 30, n 24, pp. 21-28, Aug. 25, 2010.

[17] Minh-Khai Nguyen, Young-Gook Jung, and Young-Cheol Lim, "Single-phase AC/AC buck-boost converter with singlephase matrix topology," in Proc. 2009 13th European Conference on Power Electronics and Applications, EPE '09, 2009.

[18] Kiwoo Park, Eun-Sil Lee, and Kyo-Beum Lee, “A Z-source sparse matrix converter with a fuzzy logic controller based compensation method under abnormal input voltage conditions," in Proc. IEEE International Symposium on Industrial Electronics, ISIE 2010, 2010, pp. 614-619.

[19] Kiwoo Park and Kyo-Beum Lee, "A novel sparse matrix converter with a Z-source network," in Proc. 35th Annual Conference of the IEEE Industrial Electronics Society, IECON 2009, 2009, pp. 4487-4492.

[20] Tuyen D. Nguyen, Hoang M. Nguyen, Hong-Hee Lee, and Tae-Won Chun, "An approach of sparse matrix converter using Z-source network," in Proc. 2010 International Power Electronics Conference-ECCE Asia, IPEC2010, 2010, pp. 2774-2780.

[21] Kiwoo Park and Kyo-Beum Lee, "A Z-source sparse matrix converter under a voltage sag condition," in Proc. 2010 IEEE Energy Conversion Congress and Exposition, ECCE 2010, 2010, pp. 2893-2898.

[22] Fang Z. Peng, "Revisit power conversion circuit topologiesRecent advances and applications," in Proc. 2009 IEEE 6th International Power Electronics and Motion Control Conference, IPEMC '09, 2009, pp. 188-192.

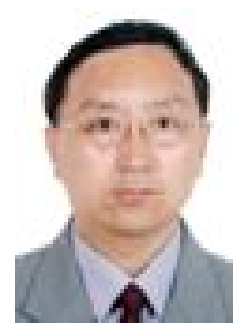

Xupeng Fang received his B.S. and M.S. degrees from Shandong University of Science and Technology, Qingdao, China, in 1994 and 1997, respectively, majored in industry automation and electrical engineering, respectively, and Ph.D. degree from Zhejiang University, Hangzhou, in 2005, in electrical engineering.

He joined Shandong University of Science and Technology, Qingdao, China, in 1997 and now he is an Associate Professor in the College of Information and Electrical Engineering. He has published more than 20 papers in IEEE Transactions and IEEE conference proceedings, and holds 7 patents. His research interests include Z-source converter and its applications, utility applications of power electronics such as active filters and FACTs devices, renewable resources generation.

Dr. Fang is a senior member of China Electrotechnical Society and Power Electronics Society, and invited reviewer of IEEE Transactions on Power Electronics, IEEE Transactions on Industrial Electronics, IEEE Transactions on Circuits and Systems and Transactions of China Electrotechnical Society, etc.

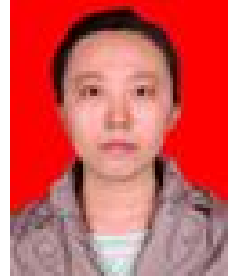

Jie Liu received her B.S. degree from Shandong Jiaotong University, Jinan, China, in 2010, majored in automation, and now she is pursuing M.S. degree in Shandong University of Science and Technology, Qingdao,China, majoring in power systems and automation. Her research interests are emerging energy systems, electric machines and Z-source converter and its applications. 